\title{
Análisis del Discurso Publicitario de la tienda FES: Amores que Matan, Show de Cobardes
}

\section{Advertising Discourse Analysis of FES stores: Killing Love, Cowards Show ${ }^{\text {*** }}$}

\author{
Cristian A. Venegas Ahumada ${ }^{2 *}$ \\ Universidad Santo Tomás, Viña del Mar, Chile
}

(Recepción: Diciembre 2008 - Aceptación: Abril 2009)

\begin{abstract}
Resumen
El objetivo es analizar el discurso estructural y fotográfico de la campaña publicitaria Otoño-Invierno 2008 de la tienda de ropa juvenil FES, desde una teoría semiótica y una metodología de análisis crítico-estructural de discurso. Se realizó un análisis a 4 fotografías publicitarias y al discurso "FES dice no a la violencia contra la Mujer”, que explica el objetivo de la campaña. El resultado es: El discurso sometido a la condición de producción (sociedad del control) hace de la publicidad una forma de homogenizar la subjetividad de las masas para que consuman. Las condiciones de reconocimiento demuestran que la violencia simbólica hace de este discurso publicitario una forma de violación de los derechos de Hombres y Mujeres. Un hecho como este requiere del compromiso de la Psicología para promover el cambio social humanizador, tanto en la enseñanza universitaria como en su ejercicio profesional.
\end{abstract}

Palabras claves: Sociedad del control, discurso publicitario, violencia simbólica.

\begin{abstract}
The objective is to analyze the structural and photographic discourse of the Autumn-Winter campaign 2008 of FES stores for young people. This was done by a semiotic theory and a critical-structural methodology of discourse. An analysis of 4 advertising photographs was done, and at once an analysis of the discourse "FES says no to violence against Women”, which explains the campaign's target. The result is: The discourse was subjected to production condition (society of control) and makes advertising a way to homogenize subjectivity of masses to consume. Recognition conditions demonstrate that this advertising discourse of symbolic violence means a type of violation of Men and Women Rights. An action like this requires commitment of Psychology in order to promote the social humanizing change, by means of university teaching and professional tasks.

Key words: Society of control, advertising discourse, symbolic violence.
\end{abstract}

\footnotetext{
$1^{* *}$ Se agradece el trabajo realizado por Tania Ponce Luke, Traductora e Intérprete en Inglés, que le ha permitido al presente estudio cumplir con un requisito fundamental para su publicación.

2 *Correspondencia a: Cristian Venegas Ahumada, Universidad Santo Tomás, Viña del Mar, Chile. E-mail: cristianvenegasahumada@yahoo.es
} 


\section{Introducción: La Persistencia de la Memoria ${ }^{3}$.}

La tienda FES es una empresa Chilena que se especializa en venta de ropa, calzados y accesorios para el segmento juvenil. La mencionada marca ha realizado campañas publicitarias que han causado polémica y gran impacto público, evidenciado en la cobertura entregada por los periódicos, noticieros y páginas de Internet. El motivo: la inusitada violencia contenida en sus campañas publicitarias ${ }^{4}$. Respecto a ellas -sólo por nombrar algunas-, cronológicamente, es posible citar: Love Death and Chocolate Story- Otoño-Invierno- (2005), en la cual se apreciaban balazos, disparos, asesinatos, cortes, sangre y hematomas, impactantes por su crudeza y realismo. (Lechuga, 2005; CONAR, 2005 citado en Venegas, 2006b; Venegas, 2006b, 2007). Luego, New Lolitas Juegan Sucio - Primavera Verano 2006-, en donde aparecían mujeres tratando a los hombres como animales, esclavos, sometidos por la fuerza mediante instrumentos sadomasoquistas (Las Últimas Noticias, 2006). Finalmente, la actual campaña -Otoño Invierno 2008-, Amores que Matan, Show de Cobardes, persevera en la línea temática, siendo nuevamente denunciados al Concejo Nacional de Autorregulación y Ética Publicitaria que ha emitido un Dictamen Ético que sugiere a FES el retiro de la campaña (CONAR, 2008), no siendo acatado por los dueños de la tienda.

Desde un punto de vista psicosocial jurídico el discurso de la campaña publicitaria de la tienda FES del 2005 ha tenido un contenido cualitativo de violencia simbólica contra la Mujer y el Hombre por sus contenidos: Agresión hostil, sexismo, prejuicio, discriminación, estereotipo y violencia de género, vulnerándose la Constitución Política de la República de Chile, El Código de Ética Publicitaria, la Convención para la Eliminación de Todas las Formas de Discriminación contra la Mujer, ratificada por Chile y los Derechos Humanos. Así ha quedado de manifiesto que en una cultura patriarcal y en un sistema económico neoliberal como el nuestro, la tienda FES ha defendido intereses económicos ${ }^{5}$ por sobre: el respeto a la dignidad humana, la ética y las leyes, garantes principales -pero no las únicas- del orden social justo y de la Democracia (Venegas, 2006b, 2007).

El Discurso publicitario de FES respecto del Objeto (cuerpo femenino), está sometido a Condiciones de Producción (Sociedad del Control) y Condiciones de Reconocimiento, que aúnan en la memoria histórica los siguientes elementos: el recuerdo del contenido violento de las anteriores campañas de FES, la conciencia social del femicidio en Chile, la reivindicación de los Derechos de la Mujer, la Constitución Política de la República de Chile, El Código de Ética Publicitaria, la Convención para la Eliminación de Todas las Formas de Discriminación Contra la Mujer y los Derechos Humanos.

El planteamiento del problema podemos definirlo como: ¿Cuál es el sentido del Discurso de la Campaña Publicitaria Otoño-Invierno $2008^{6}$ de FES, sobre el Objeto (cuerpo femenino), considerando sus Condiciones de Producción (Sociedad del Control) y sus Condiciones de Reconocimiento (memoria histórica)?

La presente investigación tiene por objetivo analizar el Discurso estructural y fotográfico de la campaña publicitaria Otoño- Invierno 2008 de la tienda FES, desde una teoría semiótica y estructural con análisis crítico de discurso. Para tal efecto, en primer lugar, se procederá a identificar en las fotografías publicitarias los contenidos presentes, a partir de categorías a priori que provienen de la semiótica y el diseño. En segundo lugar, se realiza un análisis del discurso escrito realizado por la empresa, titulado "FES dice no a la violencia contra la Mujer" en él se refieren al propósito de la campaña publicitaria.

Los antecedentes señalados sobre el caso FES, permiten la utilización de la memoria (Programa de Naciones Unidas para el Desarrollo [PNUD], 2000) respecto de la historia reciente, para dotar

3 Título inspirado en el cuadro del mismo nombre pintado por el español Salvador Dalí en 1931.

4 Entrando al portal Web www.fesjeans.com en la sección “Campañas Anteriores”, se podrán ver las fotografías publicitarias aludidas, según diseño Web vigente al 24 de Abril del 2009.

5 Se hace referencia al dinero invertido en la campaña publicitaria

6 Ver “Anexo: Fotografías Publicitarias de FES Campaña Otoño-Invierno 2008”. 
de sentido la actual campaña, a la luz de un análisis crítico de discurso, que utiliza de la Teoría Semiótica y del Estructuralismo como interpretantes del discurso publicitario. Esto hace que la investigación resulte relevante desde un punto de vista teórico, metodológico y disciplinario, por cuanto el estudio propuesto es una acción social enmarcada en una ética profesional comprometida con la responsabilidad social, la integridad física y psíquica de las personas, y, en general, promueve el respeto a los Derechos Humanos (Colegio de Psicólogos de Chile, 1999).

\section{Antecedentes Teóricos.}

\section{El Discurso Publicitario de la tienda FES en sus Condiciones de Producción y Reconocimiento.}

El Discurso Publicitario es un "conjunto de prácticas lingüísticas [y pictóricas] que mantienen y promueven relaciones sociales” (Iñiguez, 2003, p. 204), constituye un Objeto [O] respecto de la representación del cuerpo femenino mediante la Publicidad Lingüístico-Fotográfica, que contiene violencia simbólica7. Además, este discurso posee "huellas" de las Condiciones de Producción propias de una Sociedad del Control. Donde el control se caracteriza por ser continuo y encontrarse diseminado por toda la sociedad, adoptando formas siempre cambiantes, tendiendo cada vez más hacia la impersonalidad del ejercicio del control, la transnacionalización, el predominio del lenguaje numérico, la utilización de la informática y máquinas como los computadores. Esto evidencia una transformación del capitalismo -cuya esencia se encontraba en la producción y en la acumulación de riquezas- a un capitalismo de productos, ventas y mercados; teniendo en el marketing y la publicidad las formas de control contemporáneas más poderosas en tanto permanecen en mutación permanente (Deleuze 1999).

En la sociedad contemporánea se ejerce un control cuyos efectos individuales y sociales son síntomas psíquicos, somáticos, conductas de riesgo, endeudamientos, vulnerabilidad, exclusión social, protestas y disturbios. En otras palabras en la sociedad del control deben enfrentarse los efectos negativos sobre las esferas individuales y sociales (Deleuze 1999).

Si las campañas publicitarias de la tienda FES contienen violencia y vulneran la ética publicitaria, la Constitución, los Derechos Humanos y los Derechos de la Mujer (Venegas, 2006b, 2007; CONAR, 2008), ¿qué hace que ese Poder vulnerador sea aceptado?, "lo que hace que el poder se acepte, es simplemente que no pesa solamente como una fuerza que dice no, sino que de hecho va más allá, produce cosas, induce placer, formas de saber, produce discursos" (Foucault, 1992, pp. 192193). Por tanto, debemos entender que la práctica discursiva de la campaña publicitaria refuerza el imaginario social ${ }^{8}$ propio de la subjetividad contemporánea, haciendo del consumo, la única alternativa postmoderna presentada por el sistema para alcanzar éxito, poder, elegancia, belleza, sensualidad, placer y estatus. Sin embargo, en una sociedad como la nuestra, erigida sobre una cultura patriarcal $l^{9}$, la violencia es legitimada como medio y fin en la búsqueda de los/las sujetos/ sujetas por encarnar lo imaginario, sintiendo en ello no la herida de la vulneración sino el placer del cumplimiento del deseo social-individual.

El Discurso está formado por signos lingüístico-fotográficos, metafóricamente son una "punta del iceberg", lo manifiesto, que permite su visibilidad gracias a una sumergida y densa Estructura. Esta última puede definirse como una totalidad provista de una regulación emanada de sí misma, resistente al tiempo. Si no impone inmovilidad, connota una duración capaz de atravesar temporalidades y

7 Es "todo poder que logra imponer significaciones e imponerlas como legítimas disimulando las relaciones de fuerza en que se funda su propia fuerza, añade su fuerza propia, es decir, propiamente simbólica, a esas relaciones de fuerza” (Bourdieu \& Passeron, 2001, p. 18).

8 Es una representación global generada desde todos los puntos del poder, cuya realidad reside en su propia existencia, en tanto ha sido inventada y elaborada con signos y símbolos culturales que confieren una identidad, legitiman el poder y le confieren protección a éste por la vía de reproducir en las mentalidades y comportamientos colectivos (Baczko, 1999) los signos que favorecen el consumo.

9 se caracteriza por la guerra, la competencia, las luchas, las jerarquías, la autoridad, el poder, el control, la negación de lo diferente y un modelo dominador/a / dominado/a (Eisler, 1993; Maturana, 1997). 
sobrepasarlas (Hernández, 1973). De este modo, se puede afirmar que "las propiedades lógicamente conocibles del Objeto [en este caso los códigos lingüístico-fotográficos de la publicidad] respecto del cuerpo femenino, se despliegan como relaciones con otros objetos en el seno de una estructura en la que este objeto no es más que el nudo de una trama” (Granger, 1970, p. 82). La estructura aludida sólo se hace visible mediante un análisis estructural de discurso, revelador de aquello que ya aparece naturalizado en el discurso social publicitario.

Las Condiciones de Reconocimiento están contenidas en la memoria, definida como "la interpretación en presente de las experiencias del pasado, con el fin de obtener una orientación en el presente o un sentido para el futuro" (Programa de Naciones Unidas para el Desarrollo [PNUD], 2000, p. 58). Esta memoria histórica está constituida por los siguientes elementos relacionales: el recuerdo del contenido violento de las anteriores campañas de FES, la conciencia social del femicidio en Chile, la reivindicación de los Derechos de la Mujer, la Constitución Política de la República de Chile, El Código de Ética Publicitaria, la Convención para la Eliminación de Todas las Formas de Discriminación Hacia la Mujer y los Derechos Humanos, tal como se sintetiza en el cuadro "Disposiciones Normativas Aplicables al Contenido de la Publicidad"10.

El ejercicio profesional de la Psicología necesita actualmente de un profundo compromiso para denunciar situaciones de injusticia, promover la solución de problemas sociales ${ }^{11}$ y contribuir a la construcción de una sociedad más justa y democrática, lo cual significa, entre otras cosas, actuar cumpliendo el Código de Ética del Colegio de Psicólogos de Chile, aplicable al presente caso en virtud del Art. $1^{\text {o: }}$ "El/La psicólogo/a se compromete a respetar y adherir a los principios establecidos en la Declaración Universal de los Derechos Humanos" (Colegio de Psicólogos de Chile, 1999, p. 6). Esta disposición se complementa con el Art. $6^{\circ}$ que señala: “El/La psicólogo/a tendrá presente su responsabilidad profesional y científica hacia la comunidad y la sociedad en que trabaja y vive. Asimismo su compromiso social implicará aportar al conocimiento, estudio y transformación de su sociedad, y la promoción y desarrollo de leyes y políticas sociales que apunten, desde su especificidad profesional, a crear condiciones que contribuyan al bienestar y desarrollo de la comunidad” (Colegio de Psicólogos de Chile, 1999, p. 7). Los artículos citados intervienen como Condiciones de Reconocimiento que permiten dotar de sentido la campaña publicitaria de FES y la acción social de análisis de la misma, haciendo de la práctica de la Psicología una acción política que promueve el cambio social, por cuanto se transforma en un modo de deconstruir el discurso dominante y abrir vías alternativas de concebir lo real. Esto es, sembrar las semillas de una verdadera y profunda revolución simbólica; para que ésta se lleve a efecto "debe transformar las interpretaciones del mundo, es decir, los principios según los cuales se ve y se divide el mundo natural y el mundo social, y que, inscritos en forma de disposiciones corporales muy poderosas, permanecen inaccesibles al influjo de la conciencia y de la argumentación racional” (Bourdieu, 1995, p. 5).

10 Leyes en las cuales Fundación Instituto de la Mujer ha fundado el Recurso de Protección interpuesto contra FES por la campaña de Publicitaria que también contenía violencia contra la Mujer (Venegas, 2006b).

11 "Existe un problema social cuando un grupo de influencia es consciente de una condición social que afecta a sus valores, y que puede ser remediada por una acción colectiva "(Sullivan et al, 1980 citado en Clemente, 1992, p. 16). A su vez, se entenderá por condición social “[...] la característica en cuya presencia nace un problema social, siendo por tanto el problema social más bien la consecuencia, o mejor dicho uno de los posibles productos que se manifiestan al estar presente tal condición social” (Clemente, 1997, p. 13). 
Disposiciones Normativas Aplicables al Contenido de la Publicidad.

\begin{tabular}{|c|c|}
\hline Convención Internacional de Derechos Humanos (DDHH, 1969). & $\begin{array}{c}\text { Convención para la Eliminación de Todas las Formas de } \\
\text { Discriminación Hacia la Mujer (CEDAW, 1979). }\end{array}$ \\
\hline 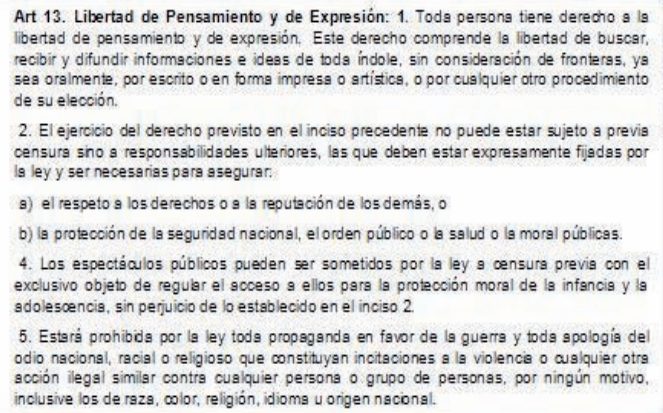 & 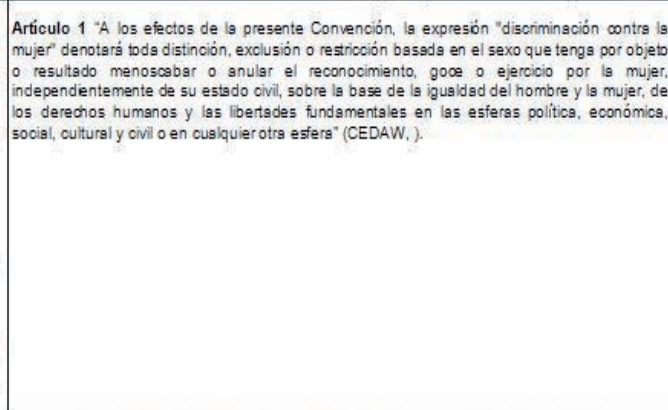 \\
\hline Constitución Política de la República de Chile (CPE, 2008). & Código Chileno de Ética Publicitaria (CCHEP, 2007). \\
\hline $\begin{array}{l}\text { Art. } 19 \mathrm{~N}^{0} 1 \text { : "El derecho a la vida y a la integridsd Fisica y psiquica de la persona" (CPE, } \\
2008, p .15 \text { ). } \\
\text { Art. } 19 \mathrm{~N}^{\circ} 4 \text { "Respeto y Protección a la vids privgds y públics y a la honrs de la persons" } \\
\text { (CPE, 2008, p. 16). }\end{array}$ & $\begin{array}{l}\text { Considerando E: "Como actvidad onientada fundamentamente al ben común, los } \\
\text { avisadores y las agencias deberán centir su acción a la realidad económica, cultural, } \\
\text { social y educacional que viva la comunidad en el momento en que se desarrolla la } \\
\text { comunicación" (CCHEP, 2007, p. 2) }\end{array}$ \\
\hline 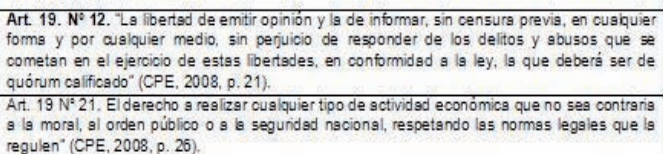 & \multirow{2}{*}{$\begin{array}{l}\text { Art. } 3^{\circ} \text {. "Los mensajes no deben inducir a realizar o apoyar actos de violencia en } \\
\text { cualquiera de sus manifestaciones, ni sugerirán que con ellos podrán obtenerse ventajas } \\
\text { o beneficios" (CCHEP, p. 3). "A respecto, se debe consignar, que este Directorio estima } \\
\text { que esta disposición debe ser entendida no sólo como una sanción a cualquier apologia } \\
\text { de la violencia en la comunicación publicitaria, sino también como una restricción al uso de } \\
\text { manifestaciones o representaciones de la misma, que la exacerben o hagan uso de la } \\
\text { truculencia o de representaciones de conductas que exalten la crueldad o abusen del } \\
\text { sufrimiento, del pánico o del horror, sin una adecuada justificación" (Dictamen Etico } \\
\text { CONAR, 2008, p.5). }\end{array}$} \\
\hline 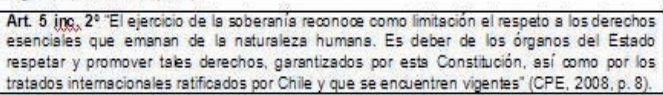 & \\
\hline
\end{tabular}

Las Condiciones de Producción, y las Condiciones de Reconocimiento señaladas respecto del Discurso publicitario, que tiene por Objeto una determinada representación del cuerpo femenino, está construida como una Publicidad de naturaleza lingüístico-fotográfica, vinculadas a una teoría y metodología semiótica ${ }^{12}$ - estructuralista ${ }^{13}$. Desde la perspectiva teórica-metodológica propuesta el fenómeno social ha investigar, es una interacción en donde se constituye el sentido en cuanto semiosis social. Lo señalado, se encuentra en el esquema siguiente, adaptado a partir de los planteamientos de Verón (1987).

12 Su objeto de estudio son "los modos de producción de la significación social [...] se propone el análisis de la dimensión significante de todo hecho desde el momento en que se asigna su pertinencia: el régimen de determinaciones objetivas que hacen significativo a lo real” (Sercovich, 1973, pp. 11-12).

13Es un método que “consiste en discernir formas invariantes en el seno de contenidos diferentes” (Lévi-Strauss, 2001, p. 260). Su objeto de estudio son las relaciones invisibles. Esta metodología asume que lo manifiesto oculta la condición esencial de lo real (Calello \& Neuhaus, 1999). 


\section{La Semiosis Discursiva $^{14}$}

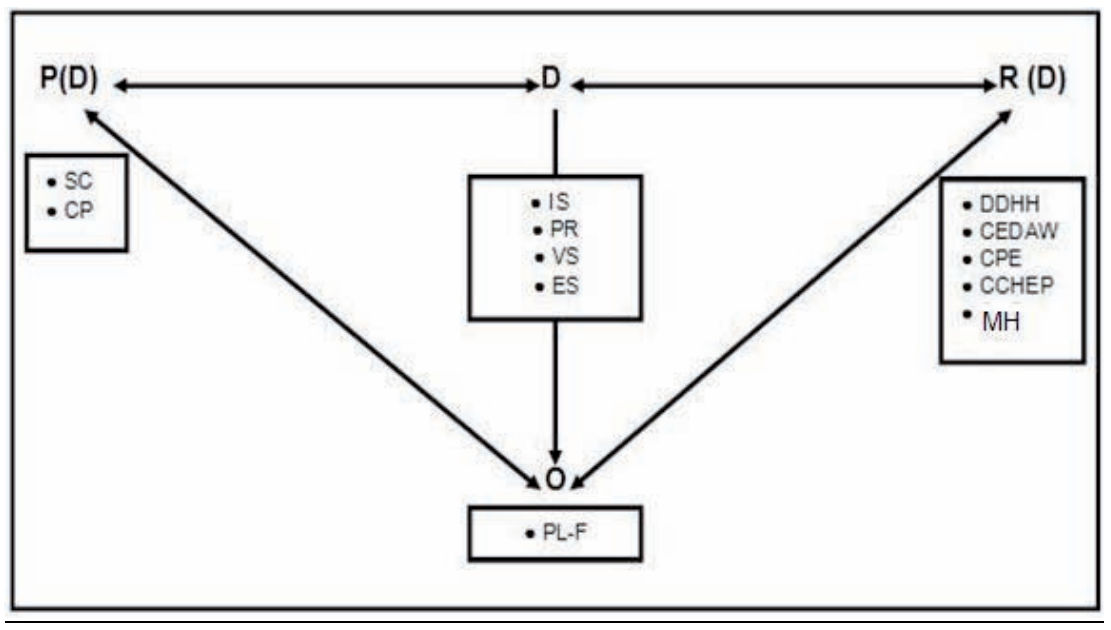

\subsection{El Discurso Publicitario como Retórica de la Imagen ${ }^{15}$.}

La fotografía es en lo esencial, un Discurso constituido por líneas, superficies y tonos. La fotografía es un analogon de la realidad, por tanto es un mensaje sin código, es un mensaje continuo. Existe además un mensaje suplementario cuyo significante está relacionado con un "tratamiento" de la imagen por acción directa de su creador, cuyo sentido remite a la cultura (Barthes, 1992) entendida como "[...] sistemas en interacción de signos ${ }^{16}$ interpretables ([...] símbolos) [...] es un contexto dentro del cual pueden describirse [los] fenómenos de manera inteligible” (Geertz, 2001, p. 27). La caracterización realizada hace que la fotografía publicitaria en tanto que imagen, esté diseñada mediante una determinada composición ${ }^{17}$, definida como la distribución o disposición de todos los elementos incluidos en un diseño fotográfico, en este caso, para construir un determinado discurso visual (FOTONOSTRA, 2008).

\subsubsection{El Perfil de Atracción.}

Corresponde al recorrido perceptivo realizado por el /la receptor/a de la imagen publicitaria, que puede ser objetivado, haciendo una correcta lectura del anuncio publicitario mediante una analogía entre el mensaje icónico y el lingüístico. Los factores esenciales de la imagen recién aludidos pueden agruparse en categorías polares:

$14 \mathrm{P}(\mathrm{D})=$ Condiciones de Producción del Discurso; SC= Sociedad del Control; $\mathrm{CP}=\mathrm{Cultura}$ Patriarcal; D=Discurso; Imaginario Social=IS; Poder=PR; VS=Violencia Simbólica; ES= Estructura; O= Objeto; PL-F=Publicidad LingüísticaFotográfica. R(D)=Condiciones de Reconocimiento del Discurso; DDHH=Derechos Humanos; CEDAW=Convention on the Elimination of All Forms of Discrimination against Women (Convención sobre la Eliminación de todas las Formas de Discriminación Contra la Mujer); CPE= Constitución Política del Estado de Chile; CCHEP= Código Chileno de Ética Publicitaria; $\mathrm{MH}=$ Memoria Histórica

15 Considerando el gran número de variables aplicadas para el análisis y la acotada extensión conferida en el presente medio, se definirán de modo sintetizado sólo algunas de las variables.

16 Según (Peirce, 1903) un signo es “[...] algo que para alguien, representa o se refiere a algo en algún aspecto o carácter. Se dirige a alguien, esto es, crea en la mente de esa persona un signo equivalente, o, tal vez, un signo más desarrollado [...]. El signo está en lugar de algo, su objeto. Está en lugar de ese objeto, no en todos los aspectos, sino sólo con referencia a una suerte de idea” (p. 22).

17Esta variable engloba a su vez: textura, signos, espacio, líneas, forma, proporción, equilibrio, armonía, colores, contraste, color denotativo, color connotativo, tipos de composición, proporción, angulación, composición geométrica, luz, contrastes, cuadrantes, texto y Leyes de la composición. 
1. Tamaño ${ }^{18}$ : grande/ pequeño.

2. Color: coloreado / tenue.

3. Plano: próximo /lejano.

4. Nitidez: nítido / vago.

5. Luminosidad: Luminoso /oscuro.

Las categorías polares poseen además una variación cualitativa, así puede variar entre: Muy, Bastante, Casi, Neutro. Ej.: Muy Grande, Bastante Nítido, Casi Tenue, etc. (Baraduc, 1993 en Boscán \& Mendoza, 2004).

\subsubsection{Semiótico / Social.}

La dimensión semiótica de la fotografía se refiere a los procedimientos de connotación ${ }^{19}$ utilizados por la agencia publicitaria para construir un cierta retórica con el discurso icónico allí desplegado. Se trata de la manipulación de elementos que hacen significante al mensaje publicitario por la acción misma de sus creadores. En otras palabras, en la acción desplegada es manifiesta la intencionalidad o sentido buscado, para remitir así a los/las receptores/as del mensaje a un conjunto acotado de significaciones.

Para establecer el sentido que las fotografías tienen para el público y para el / la propio/a analista de este discurso, la Fenomenología ${ }^{20}$ sostiene que los seres humanos no viven en un mundo objetivo cuya existencia es impuesta, sino en un mundo que es dotado de sentido subjetivamente por el ser humano. Es por eso que la significación de la fotografía reside en la conciencia de quien percibe, que al estar en un contexto cultural determinado limita los posibles sentidos de la fotografía.

Los Procesos Psicosociales son los modos en que los/las individuos/as mantienen determinadas interacciones con el medio sociocultural, haciendo que la aludida relación sea el foco de análisis. Desde esta perspectiva resulta fundamental el concepto de violencia simbólica, entendida como "todo poder que logra imponer significaciones e imponerlas como legítimas disimulando las relaciones de fuerza en que se funda su propia fuerza, añade su fuerza propia, es decir, propiamente simbólica, a esas relaciones de fuerza” (Bourdieu \& Passeron, 2001, p. 18). Este concepto cobra especial relevancia a la hora de comprender que la publicidad promueve la mantención de ciertas significaciones respecto de lo que es ser Mujer y Hombre en una sociedad determinada, en otras palabras, construye el género, sin embargo, en una cultura patriarcal como la nuestra, se reproducen imágenes sexistas y estereotipos de género, naturalizados por la ideología neoliberal publicitaria, mediante una estrategia que consiste en dotar a esos cuerpos de un lugar propio del deseo sociocultural hegemónico, haciendo del rutilante brillo y de la sensualidad proyectada, una objetualización del cuerpo, mediante el placer-poder, que se adentra en la subjetividad de los/las sujetos deseantes a quienes va dirigida la publicidad, para así incentivar el consumo. En otras palabras la publicidad se convierte en una fábrica de deseos.

Los medios de comunicación masiva son considerados uno de los agentes responsables de la socialización, es decir, de la transmisión de normas, valores y el sistema de creencias propias de una sociedad históricamente situada y que influyen en el establecimiento de la personalidad y de la identidad individual y social. En este aprendizaje los valores pueden ser definidos como orientaciones, cualidades no sustantivas, guías para evaluar, normas para la conducta. Designan un conjunto de creencias relativamente permanentes que definen comportamientos socialmente más adecuados o preferibles para determinadas situaciones. Los valores son un punto medio entre dos extremos o polaridades (Aristóteles en Bravo, 1995; Correa, Orellana, Varas, Zamora, 1991;

18 Muy pequeño: 1/8. Bastante Pequeño: 2/8. Casi Pequeño: 3/8. Neutro: 4/8. Casi Grande: 5/8. Bastante grande 6/8. Muy Grande: $7 / 8$ a $8 / 8$.

19 Ver detalles de las variables agrupadas bajo estas categorías pueden revisarse en Venegas (2007).

20Ibíd. nota 14. 
Frondizi, 1990; López, 1992). Definido de este modo, la publicidad, por tanto, socializa en valores y también en disvalores (por ausencia o exceso), resultando fundamental a la hora de analizar su discurso como formador de subjetividades.

\subsubsection{Actantes.}

Esta categoría pone de relieve el comportamiento de las personas que aparecen en las fotografías publicitarias, permitiendo con ello caracterizar el perfil de quienes aparecen representados. Así, se consideran aspectos como la manera en que aparece el cuerpo ${ }^{21}$, las expresiones faciales de la emoción $^{22}$, sentimientos ${ }^{23}$, pasiones $^{24}$ (cólera, odio, tiranía), posición de deseo (de el o la sujeto/ objeto). Finalmente se considera la Raza (Blanca, Negra y Amarilla) y el Tipo Morfológico ${ }^{25}$, para así inferir la intencionalidad del Discurso lingüístico-fotográfico (Boscán \& Mendoza, 2004).

\subsubsection{Escala de Iconicidad.}

La Escala de Iconicidad ${ }^{26}$ permite medir el grado de realismo de la imagen, estando configurado por la relación entre la norma representativa en una sociedad y cultura determinada y su particular modo de representación (Aumont, 1990 en Franco, 2004). Por ejemplo una fotografía en blanco y negro es menos icónica que una fotografía a color, porque la fotografía en colores restituye las propiedades pictóricas en un abanico de posibles colores. En consecuencia, el aludido instrumento resulta adecuado para medir el grado de ajuste entre la imagen y la "realidad".

\section{Objetivos.}

\section{Objetivo General:}

1. Analizar el Discurso estructural y fotográfico de la campaña publicitaria Otoño-Invierno 2008 de la tienda FES, desde una teoría semiótica con análisis crítico- estructural de discurso.

\section{Objetivos Específicos:}

1.1. Relacionar las Condiciones de Producción (Sociedad del Control) con la Composición, Perfil de Atracción y dimensión Semiótico social de las fotografías de la campaña publicitaria.

1.2. Relacionar las Condiciones de Producción (Sociedad del Control) con las variables que resulten predominantes en: Composición, Perfil de Atracción, Semiótico/Social, Actantes y Escala de Iconicidad.

1.3. Determinar la relación entre el Objeto (cuerpo femenino) del Discurso de la campaña publicitaria y la Condición de Reconocimiento (memoria histórica) vinculada a campañas publicitarias anteriores de FES y al Problema Social de la violencia contra la Mujer.

21 Totalmente desnudo, parcialmente desnudo, en ropa interior, insinuante, vestimenta informal, vestimenta formal, vestimenta de gala ó vestimenta fantasiosa.

22 Definiremos por emoción "una agitación interior que se produce como consecuencia de sensopercepciones, recuerdos, pensamientos, juicios y que va a producir una vivencia, unas manifestaciones fisiológicas, un tipo de conducta y unas experiencias cognitivas” (Rojas, 1989, p. 21). Las emociones son: Alegría, tristeza, miedo, sorpresa, enojo, asco.

23 Se definen como "un estado subjetivo difuso, que tiene siempre una totalidad positiva o negativa” (Rojas, 1989, p. 59). Los sentimientos son: Satisfacción- insatisfacción, placer-displacer, tensión-relajación, felicidad-infelicidad, aburrimiento, superioridad-inferioridad.

24 Son "modificaciones intensas de la afectividad, significa una perturbación, alteración fuerte en la conducta (Rojas, 1989).

25 Estos son estructuras físicas: Ectomórfico(a) es un cuerpo linear, con adiposidad reducida, musculatura fina, tórax estrecho delgado y huesos por lo general largos y delgados; Endomórfico) es un cuerpo caracterizado por un prominente abdomen (obesidad), esqueleto pequeños y de un gran grosor de huesos; Mesomórfico es un cuerpo caracterizado por un esqueleto y huesos de un tamaño proporcionado y un gran desarrollo muscular. (Sheldon, 1942 en Universidad Católica de Chile, 2008).

26Mide el grado de isomorfismo que una imagen guarda con su referente (Franco, 2004). 
1.4. Determinar la relación entre el Objeto (cuerpo femenino) del discurso de la campaña publicitaria y las Condiciones de Reconocimiento (Constitución Política del Estado de Chile, Código Chileno de Ética Publicitaria, Convención Internacional de Derechos Humanos y Convención para la Eliminación de Todas las Formas de Discriminación Hacia la Mujer).

1.5. Identificar los artículos del Código de Ética del Colegio de Psicólogos de Chile (Condición de Reconocimiento) que permiten dotar de sentido a la acción social de análisis del Objeto (cuerpo femenino) en el discurso publicitario.

1.6. Identificar la Estructura que subyace en el discurso publicitario "FES dice no a la violencia contra la Mujer”, relacionarla con los elementos de las Condiciones de Producción (sociedad del control) y las Condiciones de Reconocimiento (memoria histórica).

\section{Preguntas Directrices.}

1. ¿Las condiciones de producción (Sociedad del control) qué "huellas” han dejado en el anuncio publicitario de la tienda FES?

2. ¿Las condiciones de reconocimiento (memoria histórica) qué sentido permiten construir respecto del contenido fotográfico de la campaña publicitaria de FES?

3. ¿Qué sentido tiene el discurso publicitario "FES dice no a la violencia contra la Mujer" considerando las condiciones de reconocimiento?

4. ¿Qué hace posible que el discurso publicitario de la tienda FES persevere en el contenido de una publicidad que vulnera los derechos de hombres y mujeres?

\section{Marco Metodológico.}

\section{Análisis Crítico de Discurso.}

El análisis de discurso se define como "estudio de las prácticas lingüísticas para poner de manifiesto las relaciones sociales promovidas y mantenidas por el discurso” (Iñiguez, 2003, p. 202). El discurso a analizar está constituido por las fotografías publicitarias de la tienda FES. La naturaleza del objeto de estudio hace necesario un análisis de discurso basado en una teoría semiótica ${ }^{27}$ y estructural para dotar de sentido dicha producción.

Desde el punto de vista social “[...] la importancia de la fotografía no sólo reside en el hecho de que es una creación sino sobre todo en el hecho de que es uno de las medios más eficaces de moldear nuestras ideas y de influir en nuestro comportamiento" (Freund, 1995, p. 8). Por eso que el análisis de la fotografía evidencia el modo en que se busca promover determinadas relaciones sociales a través del contenido del discurso publicitario en nuestra sociedad.

El Análisis Crítico de Discurso [ACD], es un planteamiento teórico-metodológico que permite estudiar problemas sociales relevantes, se centra en el estudio de las relaciones poder, dominación y desigualdad, buscando develar y divulgar aquello implícito a los discursos (Van Dijk, 1997).

\section{Tipo de Investigación.}

La investigación es de tipo exploratoria, porque “[...] el objetivo es examinar un tema o problema de investigación poco estudiado o que no ha sido abordado antes” (Hernández, Fernández \& Baptista, 1998, p. 58). Esto queda evidenciado porque sólo existen investigaciones desde un

27 Su objeto de estudio son "los modos de producción de la significación social [...] se propone el análisis de la dimensión significante de todo hecho desde el momento en que se asigna su pertinencia: el régimen de determinaciones objetivas que hacen significativo a lo real” (Sercovich, 1973, pp. 11-12). 
enfoque fenomenológico (Venegas, 2007) ó semiótico (Boscán \& Mendoza, 2004) pero que no han enfocado la publicidad misma con aspectos estructurales de nuestra sociedad contemporánea ${ }^{28}$.

\section{Diseño.}

De acuerdo a la nomenclatura tradicional, el Diseño de esta investigación es No Experimental, Transeccional o Transversal, de Corte Cualitativo, basado en el Caso Único de tipo Instrumental.

El Caso Único se define "como un sistema acotado [...] en su condición de objeto más que de proceso [...]” (Smith, 1979 citado en Stake, 1999, p. 16). Este tipo de estudio permite formular “[...] determinadas generalizaciones para el caso” (Stake, 1999, p. 19). Aumentando en especificidad, se señala que el Estudio de Caso es de Tipo Instrumental (Stake, 1999) porque al estudiar las fotografías de la campaña publicitaria Otoño-Invierno 2008 y el discurso "FES dice no a la violencia contra la Mujer”, existe "[...] una necesidad de comprensión general [de los Discursos en sus condiciones de producción y reconocimiento] y consideramos que podemos entender la cuestión mediante el estudio de un caso particular” (Stake, 1999, p. 16).

\section{Corpus.}

Está compuesto por $\mathbf{4}$ fotografías y $\mathbf{1}$ discurso titulado "FES dice no a la violencia contra la Mujer” de la campaña Otoño-Invierno 2008.

\section{Procedimientos de Análisis del Discurso Fotográfico-Estructural ${ }^{29}$.}

\section{Análisis Fotográfico.}

1. Se analiza cada fotografía publicitaria mediante:

a. La aplicación de las categorías de análisis de la "Pauta de Observación 1: Composición" para luego registrar la frecuencia acumulada para cada una de sus categorías ${ }^{30}$.

b. Se procede a la aplicación de las categorías de análisis de la "Pauta de Observación 2: Perfil de atracción”

c. Se procede a la aplicación de las categorías de análisis de la "Pauta de Observación 3: Semiótico social”.

d. Se procede a la aplicación de las categorías de análisis de la "Pauta de Observación 4: Actantes"

e. Se identifica para cada una de las fotografías el nivel que les corresponden en la "Pauta de Observación 5: Escala de Iconicidad”, para luego registrar la frecuencia acumulada para cada uno de sus niveles.

28 Para configurar el Estado del Arte en la presente investigación de ha realizado una búsqueda en la Red de Revistas Científicas de América Latina y el Caribe desde el portal http://redalyc.uaemex.mx/

29 El proceso de análisis ha sido realizado por un único juez, el autor de la presente investigación, utilizando una metodología de análisis de discurso estructural y un análisis de imágenes ambos métodos validadazos por investigaciones anteriores que han sido citadas a lo largo del presente trabajo. El aporte metodológico de la presente investigación es la complementariedad de los estructural y semiótico para dar cuenta de un nivel más profundo respecto del objeto de análisis elegido.

30Este procedimiento se repite con cada una de las restantes categorías que conforman las pautas de observación respectivas, a excepción del Perfil de Atracción, por cuanto este será objeto de un análisis general de tendencia en una visión sinóptica de cada uno de sus resultados al comparar entre las fotografías analizadas. 


\section{Análisis Estructural ${ }^{31}$.}

f. Es necesario leer la totalidad del discurso para formarse una idea preliminar y general de los contenidos.

g. Al interior de cada discurso, se numera la totalidad de los párrafos en orden correlativo. Este procedimiento de codificación establece una referencia permanente con el discurso original facilitando al lector la comprensión de los pasos analíticos.

h. Se agrupan todos los párrafos del discurso que abordan con especificidad un tema.

I. Identificar la lectura posible de un texto. En cada párrafo se deben:

I. a. Establecer categorías polares. Estas son oposiciones entre dos enunciados. Uno de ellos está presente de modo literal en el párrafo, y el segundo es el opuesto del primero, recogiendo un aspecto implícito, latente (Levi-Strauss, 2001a, 2001b, 2001c; Pérez, 1973).

I. b. Calificar el valor de cada categoría polar como positiva (+), negativa (-) y establecer si se encuentra implícito un cierto aspecto del discurso ( ).

I. c. Identificar los ejes temáticos. Son elementos estructurales implícitos, latentes, que persisten a lo largo de las categorías polares, confiriéndole a estas, unidad dentro de la diferencia (Levi-Strauss, 2001a, 2001b, 2001c; Pérez, 1973).

I. d. Establecer un Esquema o Diagrama Estructural de las relaciones entre Categorías Polares y Ejes temáticos. De este modo se permite "ver" la estructura subyacente, llegando a "[...] demostrar que elementos en apariencia dispares, no son necesariamente tales" (Levi-Strauss, 2001b, pp. 78-79).

\section{Análisis integrativo.}

j. Considerando de modo integral el contenido manifiesto como el latente posible de pesquisar con el presente análisis en sus partes I y II, se infieren procesos relacionados con las Condiciones de Producción y Reconocimiento para el Objeto cuerpo de la Mujer y su representación publicitaria junto al del Hombre.

\section{Presentación de Resultados.}

Se expondrán las pautas de observación con la frecuencia para cada una de sus categorías. Con ello se mostrará la tendencia en cada una de sus categorías ${ }^{32}$ y el Esquema Estructural que da cuenta de los aspectos manifiestos / latentes del discurso "FES dice no a la violencia contra la Mujer".

\footnotetext{
31 “Un análisis estructural, en sentido estricto, de ese corpus supone ante todo una reducción de su contenido a un conjunto de elementos tratados en adelante como elementos abstractos, o sea determinados únicamente por el sistema de sus mutuas relaciones. Esta reducción supone en general una detallada explicitación de múltiples enlaces que han pasado desapercibidos para el observador espontáneo y quizá también para el mismo autor, o los autores colectivos, del corpus analizado” (Granger, 1970, p. 85). Su objeto es la comprensión de las principios organizativos que subyacen a los planteamientos de un actor / actriz social (Martinic, 2006).Para el presente análisis se seguirá en gran parte el modelo aplicado por (Venegas, 2006a).

32 Exceptuando el Perfil de Atracción por los motivos que fueran señalados en la nota a pie de página anterior.
} 


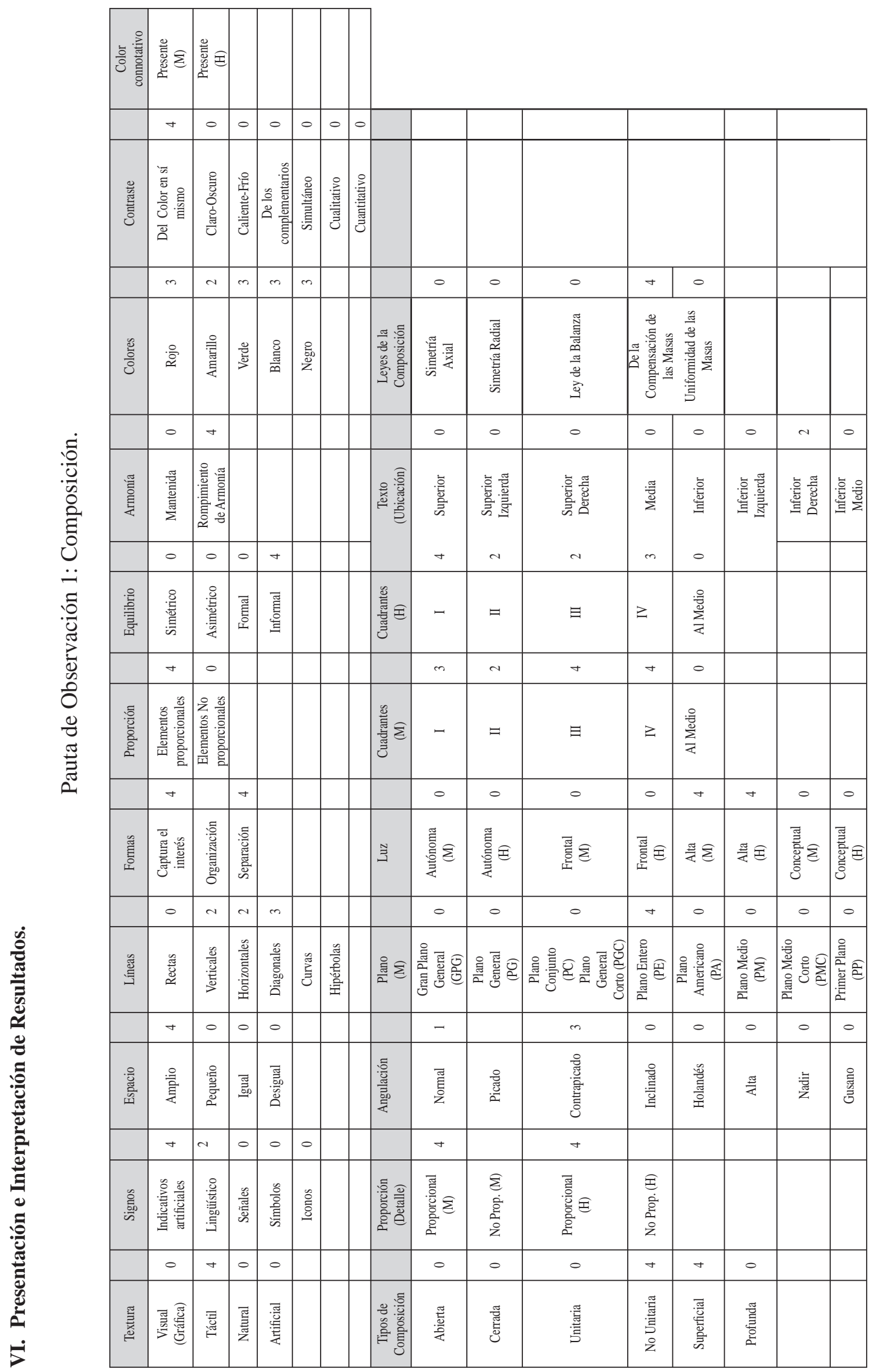


Como se trata de una publicidad de de ropa, ha utilizado una Composición en donde han puesto de relieve la textura táctil (4), es decir, la captación visual de una apariencia de superficies suaves al tacto. Con ello se percibe la ropa dotada de una calidad superior, confiriendo además estatus y distinción. Para lograr el efecto, utilizaron signos indicativos artificiales, como es, montar una escenografía, ambientación lumínica, donde el brillo de la piel, la tonalidad de la ropa han sido intervenidas para actuar como un signo que venga a representar para quien lo observa, la fuerza, el carácter trasgresor de los personajes masculinos y la sensualidad de la Mujer, en una estética sadomasoquista que lleva al límite de la representación aquello de los cual es difícil hablar: la violencia pura, ante ella el /la espectador(a) queda perplejo/a.

Las formas y las proporciones del Hombre y la Mujer en la publicidad, los dotan de un carácter indiscutidamente realista. Se suma la captura del interés en el / la espectador/a mediante la Luz Alta (4), destacándose por completo el cuerpo del Hombre y la Mujer. Así la escenificación realza una clara dualidad Hombre / Mujer, percibida en el par victimario / víctima. Con ello, se genera un rompimiento de la armonía (4) y del equilibrio (4), usando un potente contraste del color en sí mismo (4) ${ }^{33}$, dando a la violencia contenida una connotación de intensidad mayor a partir de lo pictórico, aplicando la Ley de la Compensación de las Masas ${ }^{34}$.

La representación de la Mujer y del Hombre en la Publicidad generan una Composición No Unitaria (4) y un sentido obvio o significación unívoca de la violencia (de género), aumentada por la Angulación ${ }^{35}$ (3) en contrapicado ${ }^{36}$, confiriendo un poder tiránico al victimario y subvalorando a la mujer que yace en indefensión absoluta ante la desigualdad de poder.

El realismo de la imagen viene dado por el Plano ${ }^{37}$ Entero (4) que confiere un posicionamiento completo del cuerpo del Hombre y la Mujer para aumentar la fuerza de la violencia en cuerpos representados de modo total, manteniendo la Proporcionalidad de la Mujer (4) y del Hombre (4) en la fotografía, por tanto, su adecuación a la realidad.

El Hombre aparece ocupando con mayor frecuencia el Cuadrante ${ }^{38}$ I (4), III (4) y IV (4), significando que al iniciar el recorrido perceptivo (I), entrega la información que permite interpretar de modo inequívoco el mensaje publicitario, en este caso, la desigualdad de poder del hombre (victimario) por sobre la víctima. La ocupación del III viene a cerrar el circuito perceptivo para afianzar en la imagen del hombre el poder sin contrapesos, para cerrar con el IV con información dirigida hacia lo inconsciente, cargando de fuerza y emocionalidad (rabia) la representación del hombre. Por su parte la Mujer como víctima, ocupa el Cuadrante III y IV con mayor frecuencia (4), hace del miedo, indefensión y sensualidad aquellos elementos centralmente destacados por el publicista para llamar la atención del público a través de lo más abyecto del ser humano como es transformar a alguien en un mero objeto abusable.

Finalmente las dos fotografías que tenían logo y texto, decían: "Amores que matan, show de cobardes”. El logo puntiagudo viene a reforzar el carácter agresivo. Además el emplazamiento en la esquina inferior derecha, coincide con el Cuadrante III, asociado con un lugar de síntesis perceptiva y mayor facilidad de memorizar.

33 Ejemplos: Rojo, verde, blanco y negro.

34El centro de interés se sitúa a un lado de la fotografía, en este caso, en la representación de la mujer golpeada, su rostro y actitud de víctima, siendo compensado por la fuerte pose de violencia del hombre (Posadas, 2008).

35 Es la posición del espectador que toma la fotografía (fotógrafo/a). La posición viene dada por la altura y posición adoptado/a por el /la fotógrafo/a (Posadas, 2008).

36 El/ la observador/a se sitúa por debajo del objeto, tiene un carácter de engrandecimiento y supervaloración (Posadas, 2008).

37Es la cantidad de espacio real que recoge la imagen. Cada una de las opciones sigue una escala marcada por la figura humana (Posadas, 2008).

38 Es la división de la fotografía en 4 zonas más el centro, siguiendo la dirección de las manecillas del reloj: I, II, III y IV. En ese orden visualmente los/las espectadores/as recorren y “leen” la imagen, siendo importante, toda vez que cada cuadrante posee una profundidad semiótica mayor que incide de distinto modo en el público objetivo (Boscán \& Mendoza, 2004). 
Perfiles de Atracción de las Fotografías.

Pauta de Observación 2: Perfil de Atracción Fotografía 1.

\begin{tabular}{|c|c|c|c|c|c|}
\cline { 2 - 6 } \multicolumn{1}{c|}{ Grande } & Coloreado & Próximo & \multicolumn{2}{c|}{ Nítido } & Luminoso \\
\hline 7. Muy & & & & & \\
\hline 6. Bastante & & & & & \\
\hline 5. Casi & & & & & \\
\hline 4. Neutro & & & & & \\
\hline 3. Casi & & & & & \\
\hline 2. Bastante & & & Lejano & Vago & Oscuro \\
\hline 1. Muy & & Tenue & & & \\
\hline
\end{tabular}

\section{Pauta de Observación 2: Perfil de Atracción Fotografía 2.}

\begin{tabular}{|c|c|c|c|c|c|}
\cline { 2 - 6 } \multicolumn{1}{c|}{} & Grande & Coloreado & Próximo & Nítido & Luminoso \\
\hline 7. Muy & & & & & \\
\hline 6. Bastante & & & & & \\
\hline 5. Casi & & & & & \\
\hline 4. Neutro & & & & & \\
\hline 3. Casi & & & & & \\
\hline 2. Bastante & & & & & Oscuro \\
\hline 1. Muy & & Tenue & Lejano & Vago & . \\
\hline
\end{tabular}

Pauta de Observación 2: Perfil de Atracción Fotografia 3.

\begin{tabular}{|c|c|c|c|c|c|}
\cline { 2 - 6 } \multicolumn{1}{c|}{ Grande } & Coloreado & Próximo & Nítido & Luminoso \\
\hline 7. Muy & & & & & \\
\hline 6. Bastante & & & & & \\
\hline 5. Casi & & & & & \\
\hline 4. Neutro & & & & & \\
\hline 3. Casi & & & & & \\
\hline 2. Bastante & & Tenue & Lejano & Vago & Oscuro \\
\hline 1. Muy & & & & & \\
\hline
\end{tabular}

Pauta de Observación 2: Perfil de Atracción Fotografia 4.

\begin{tabular}{|c|c|c|c|c|c|}
\cline { 2 - 6 } \multicolumn{1}{c|}{ Grande } & Coloreado & Próximo & Nítido & Luminoso \\
\hline 7. Muy & & & & & \\
\hline 6. Bastante & & & & & \\
\hline 5. Casi & & & & & \\
\hline 4. Neutro & & & & & \\
\hline 3. Casi & & & & & Oscuro \\
\hline 2. Bastante & & & & & \\
\hline 1. Muy & & Teque & Lejano & Vago & \\
\hline
\end{tabular}

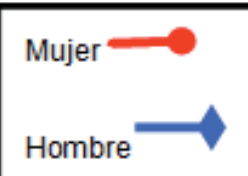


En el Perfil de Atracción ${ }^{39}$, el Tamaño de la Mujer y del Hombre en las fotografías publicitarias, es casi grande o neutro, apuntando con ello a una representación realista (proporcionalidad mantenida). La utilización de una intensidad de bastante coloreado, hace que la imagen aumente su fuerza expresiva de emoción, sentimiento y violencia contenida.

El plano de represtación de la Mujer es bastante o muy próximo, cuya intencionalidad es hacer de la víctima sufriente y cruelmente golpeada el principal estímulo abyecto de la publicidad. En particular, la Mujer, visualmente más cercana que el Hombre es en quien se concentra la expresividad emotiva, captando la atención del público.

Para aumentar aún más la fuerza perturbadora de la representación, el Hombre y de la Mujer son bastante o muy nítidos (variable nitidez) y bastante o muy luminosos (variable luminosidad). Ambas variables hacen de los cuerpos verdaderos lugares escénicos cuya perfecta resolución los vuelve de un realismo casi material, un sórdido espectáculo de violencia de género, dolor, miedo, sufrimiento y sensualidad, amalgama inverosímil a cuyo espectáculo asiste el / la atónito/a espectador/a.

39 Es un conjunto de elementos pictográficos que organizados con una estructura interna la cual permite un reconocimiento inmediato del sentido de la imagen (Boscán \& Mendoza, 2004). 


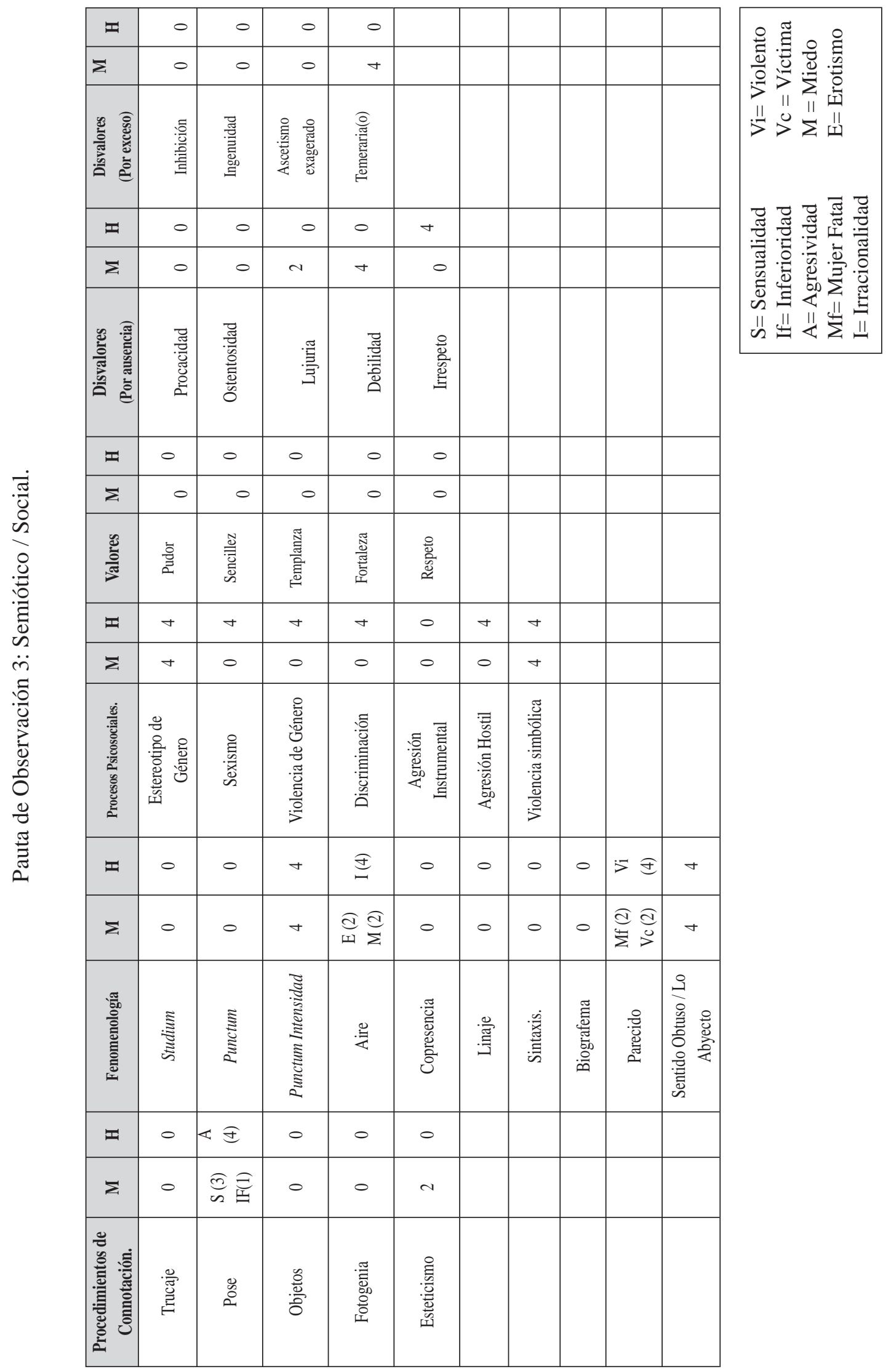


El estereotipo de género (4) está presente en todas la fotografías, representando al Hombre a partir de la construcción cultural que lo identifica como violento (4), reforzado por una pose de agresividad (4) ejercida con un aire de irracionalidad (4), en suma, una agresión hostil (4), una actitud de Hombre de irrespeto (4) y mostrándose temerario (4) hacia la mujer como disvalores por ausencia y exceso respectivamente. Considerado de este modo, el hombre ejerce una violencia de género (4) que deviene en la forma más extrema de discriminación (4) y sexismo (4) hacia la Mujer.

Por su parte, la Mujer aparece en pose de inferioridad (1), sensualidad (3) y esteticismo (2), complementado con un aire de suave erotismo (2), lujuria (2), que la hace corresponder al estereotipo de la mujer fatal (2). Sin embargo, su carácter de objeto se ve aumentado con su papel de víctima (2) débil (2) dominada por el poder sin medida del patriarca que la hace subyugar mediante la violencia. Esta se transforma en un modo de sujetar a la Mujer a su ley machista que no es otra que la impedir una merma en su poder y privilegio amenazado por la creciente emancipación femenina.

Por tanto, el análisis precedente al problematizar estas relaciones, es el primer paso para un cambio social de estas injusticias, promovidas por una publicidad que utiliza la violencia simbólica (4) y el sentido obtuso/ abyecto (4) como signos en una sociedad del control donde los/las sujetos son "sujetados", -sin ser conscientes de ello-, por una homogenización del deseo que impulsa la publicidad, una sutil pero efectiva forma de control que reproduce un orden social injusto y una economía perpetuadota de la desigualdad en la distribución del ingreso, la exclusión social y la marginalización. 


\begin{tabular}{|c|c|c|c|c|c|c|c|c|c|c|c|c|}
\hline II & $\nabla$ & 0 & & & & & & & & & & \\
\hline$\Sigma$ & 0 & $\nabla$ & & & & & & & & & & \\
\hline 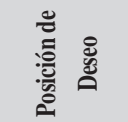 & 营 & : & & & & & & & & & & \\
\hline$I$ & 0 & $\nabla$ & 0 & & & & & & & & & \\
\hline$\Sigma$ & $\nabla$ & 0 & 0 & & & & & & & & & \\
\hline 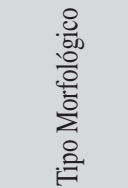 & 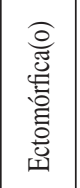 & 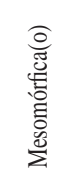 & 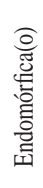 & & & & & & & & & \\
\hline$I$ & $\nabla$ & 0 & 0 & & & & & & & & & \\
\hline$\Sigma$ & $\nabla$ & 0 & 0 & & & & & & & & & \\
\hline $\begin{array}{l}\widetilde{\widetilde{U}} \\
\widetilde{\pi}\end{array}$ & 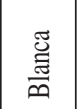 & 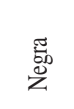 & $\begin{array}{l}\text { 营 } \\
\text { 是 }\end{array}$ & & & & & & & & & \\
\hline I & $\forall$ & 0 & 0 & & & & & & & & & \\
\hline$\Sigma$ & 0 & 0 & 0 & & & & & & & & & \\
\hline 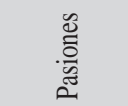 & $\frac{\frac{\pi}{2}}{0}$ & 응 & 㺃莺 & & & & & & & & & \\
\hline 工 & 0 & 0 & 0 & 0 & 0 & 0 & 0 & 0 & 0 & 0 & 0 & 0 \\
\hline$\Sigma$ & 0 & 0 & $\sim$ & 0 & $\nabla$ & 0 & 0 & 0 & 0 & 0 & 0 & $\sim$ \\
\hline 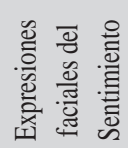 & 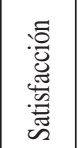 & 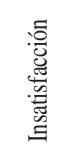 & 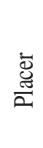 & 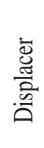 & 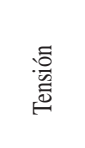 & 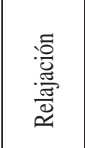 & $\begin{array}{l}\text { 虽 } \\
\text { 婸 } \\
\text { 安 }\end{array}$ & 鵸 & 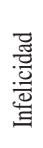 & 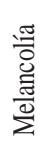 & $\begin{array}{l}\text { 莺 } \\
\text { 总 } \\
\text { 官 }\end{array}$ & 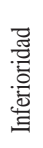 \\
\hline$I$ & 0 & 0 & 0 & 0 & $\nabla$ & 0 & & & & & & \\
\hline$\Sigma$ & 0 & 0 & $\sim$ & 0 & 0 & 0 & & & & & & \\
\hline 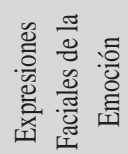 & $\frac{\pi}{\stackrel{0}{0}}$ & 莺 & 递 & 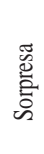 & $\begin{array}{l}\text { 을 } \\
\text { 되 }\end{array}$ & 总 & & & & & & \\
\hline$I$ & 0 & 0 & 0 & 0 & $m$ & $\rightarrow$ & 0 & 0 & & & & \\
\hline$\Sigma$ & 0 & 0 & 0 & 0 & $m$ & 0 & $\rightarrow$ & 0 & & & & \\
\hline 芯 & 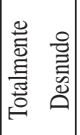 & 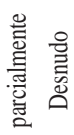 & $\begin{array}{l}\text { 总 } \\
\text { 总 } \\
\text { 蒙 } \\
\text { م. }\end{array}$ & 鴶 & 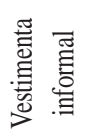 & 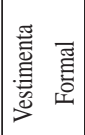 & 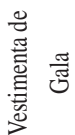 & 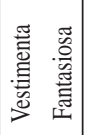 & & & & \\
\hline
\end{tabular}


Los/as actantes (hombres y mujeres) en el discurso de esta campaña publicitaria, presentan sus cuerpos vestidos con vestimentas informales (3) para lograr una identificación con el público objetivo que son jóvenes.

Para aumentar la identificación cultural de parte del público en relación al contenido de la publicidad, tanto el Hombre como la Mujer son de raza blanca (4) por cuanto se atribuye a esta el poderío, estatus, elegancia y dominación, una sofisticada forma que adopta la moda de reproducir la violencia simbólica.

Sin embargo, desde el ACD, se encuentran claros indicadores de estereotipos de género por cuanto el Hombre es presentado con la expresión faciales de enojo (4), tensión (4), arrebatado por la pasión como la cólera (4). Un cuerpo donde predomina el desarrollo muscular, es decir, mesomórfico (4), actuando como sujeto (4) de la acción retratada, en otras palabras, alguien dotado de independencia, fuerza y poder sin contrapesos, un verdadero amo, tirano patriarcal, dueño del cuerpo y la subjetividad femenina. En contraste, ella es representada con un cuerpo ectomórfico (4) y un mero objeto (4), sólo es en la medida que obedece y se hace desear, en otras palabras, sólo en la negación de su propio deseo encuentra su lugar en el patriarcado, la más profunda de las alienaciones femeninas es estar constituidas a partir del deseo masculino, cuya errónea felicidad femenina radica en complacer al varón ${ }^{40}$ : Ser objeto del deseo patriarcal.

Pauta de Observación 5: Escala de Iconicidad.

\begin{tabular}{|c|c|c|}
\hline $\begin{array}{c}\text { Grado de } \\
\text { Iconicidad }\end{array}$ & \multicolumn{2}{|c|}{ Nivel de Realidad } \\
\hline 11 & Imagen Natural & 0 \\
\hline 10 & Modelo Tridimensional a Escala & 0 \\
\hline 9 & Hologramas & 0 \\
\hline 8 & Fotografía en Color & 4 \\
\hline 7 & Fotografía en Blanco y Negro & 0 \\
\hline 6 & Pintura Realista & 0 \\
\hline 5 & Representación Figurativa No Realista & 0 \\
\hline 4 & Pictogramas & 0 \\
\hline 3 & Esquemas Motivados & 0 \\
\hline 2 & Esquemas Arbitrarios & 0 \\
\hline 1 & Representación No Figurativa & 0 \\
\hline
\end{tabular}

40 En este punto pueden citarse como ejemplos los estereotipos de género patriarcales respecto a la Mujer: Esposa, madre, musa, santa, mártir, amante y prostituta. Todos los estereotipos aludidos poseen una línea semiótica clara como es estar siempre al servicio del deseo de otro y, en consecuencia anulando su legítimo deseo que, por cierto, no es el impuesto por la cultura machista dominante. 
Esquema Estructural: El femicidio, el maltrato contra la Muier y la falta de compromiso de FES (en el Pasado). de la Sociedad y Campaña (en el Presente) para superar el problema (Futuro).
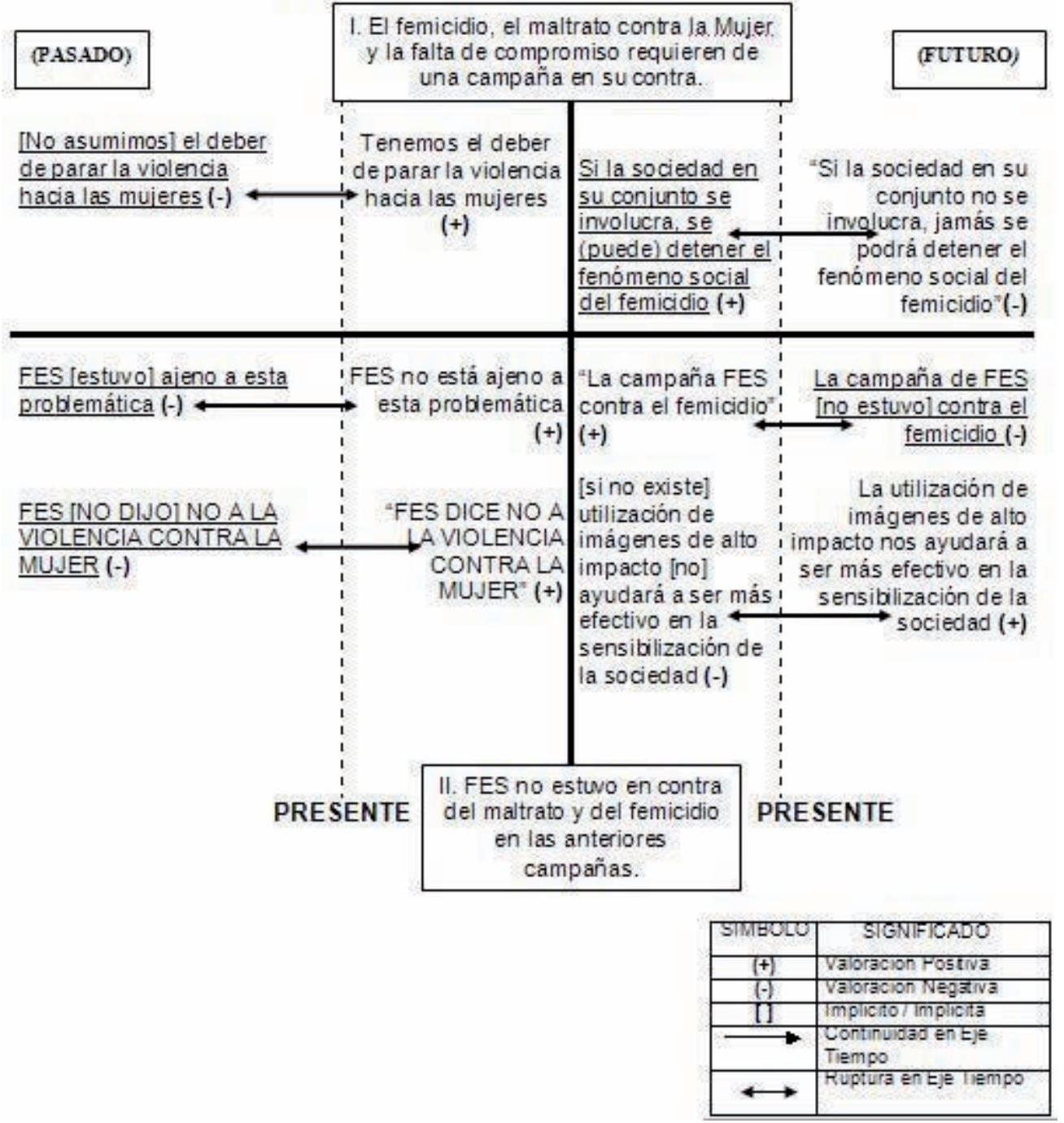

La utilización de la fotografía en color (4) se explica por un interés básicamente descriptivo por parte del publicista, esto es, mostrar la realidad "sin desdoblarla", es como si quisiera hacer de lo real un trozo captado por el lente de la cámara. Por cierto que este "interés realista” está al servicio de causar impacto por la crudeza de la imagen, tanto más potente mientras más parecida es a la realidad. Con este recurso técnico de iconicidad, logran captar con fuerza la atención del público, que complementado con las escenas de extrema violencia contenida, maximiza el efecto aludido (Franco, 2004).

Los principios organizativos de la estructura del discurso "FES dice no a la violencia contra la Mujer", ha permitido encontrar el Eje temático "I. El femicidio, el maltrato contra la Mujer y la falta de compromiso requieren de una campaña en su contra", donde la publicidad en una temporalidad presente asume el rol de comprometerse con generar conciencia en relación con el problema social del maltrato hacia la Mujer y el femicidio, acusando una falta de compromiso de la sociedad para solucionar este problema social. Subyacente al discurso textual, en el eje temporal pasado la aludida marca no asumió el deber de parar la violencia hacia las mujeres. Es más, en su campaña Otoño-Invierno 2005 hizo de la violencia hostil contra la Mujer, esto es, de la violencia 
inmotivada, impactante por su crudeza y realismo, una estrategia publicitaria para captar la atención del público. En consecuencia, este compromiso social aludido en el presente, no es sino regresar a la exitosa estrategia publicitaria anterior que permite hacer más receptivo al público mediante el uso de imágenes de violencia extrema.

La publicidad en una sociedad del control deviene en una multiforme estrategia de dominación mediante el gobierno de la subjetividad y el motor de una economía de mercado que transforma la representación del cuerpo del Hombre y de la Mujer en seres inhumanos, transformados en mercancías que produzcan ganancias económicas sin importar el Código Chileno de Ética Publicitaria, la Constitución, las Convenciones que protegen los Derechos de la Mujer ni los Derechos Humanos.

En el Eje temático "II. FES no estuvo en contra del maltrato y del femicidio en las anteriores campañas”, identifica un inconfesado interés de replegar hacia el olvido la memoria histórica que acusaría de inconsecuencia a la tienda ${ }^{41}$. Por tanto, se apoyan en la mayor conciencia y visibilización del problema social de la violencia contra la Mujer en Chile, existente en la actualidad, para utilizar este contexto como base a partir de la cual argüir un compromiso en el presente para superar esta problemática social. Bajo esta intencionalidad fundamentan la utilización de imágenes de alta crudeza y realismo para la "sensibilización" de la sociedad, cuando de verdad se trata de una nueva estrategia para maximizar sus ganancias económicas.

A modo de corolario, el análisis estructural del discurso ha revelado de modo muy potente cómo la memoria histórica señala la responsabilidad de la tienda no sólo por estar ajena a la problemática de la violencia contra la Mujer, sino de utilizarla en el pasado como en el presente como pretexto para vender sus productos. Frente a este hecho, el ACD ha visibilizado la estrategia discursiva mediante la cual FES oculta su interés económico e intenta hacer, consciente o inconcientemente, tabula rasa de su campaña anterior, sin embargo, se ha develado la violencia simbólica y la estrategia del olvido discursivamente construida.

\section{Análisis Integrativo y Global de las Condiciones de Producción y Reconocimiento para la Interpretación del Discurso Publicitario.}

Las Condiciones de Producción, aglutinadas bajo la sociedad del control hacen de la publicidad una renovada estrategia para la búsqueda de dominio del comportamiento social masivo mediante la homogenización de la subjetividad, utilizando las técnicas del diseño (composición), para crear un discurso que sintonice con el problema social del maltrato contra la Mujer y el femicidio.

El análisis estructural del discurso publicitario ha develado la estructura que sostiene el texto literal, apuntando con ello en dirección a la real intencionalidad subyacente como es la estrategia del olvido y la apariencia de una motivación de responsabilidad social; cuando de verdad sólo existe un interés económico frente al cual la ética publicitaria, la Constitución Política de Chile, los Derechos Humanos y la Convención para la Eliminación de todas las formas de Discriminación contra la Mujer se vuelven "letra muerta".

En contraste con la publicidad, forma de control del consumo masivo, verdadero motor de la economía neoliberal, las Condiciones de Reconocimiento, nos hacen pensar a "escala humana", es decir, pensar el desarrollo para el Hombre y la Mujer, no en contra de ambos, pues la publicidad, en este caso, muestra cómo destruye la dignidad de todas las personas en aras de un negocio para unos pocos. Frente a un escenario así retratado el ACD, comprometido, con la ética disciplinaria de la Psicología, hace del código una "letra viva" por cuanto se transforma en una acción concreta que hace visible y denuncia las relaciones sociales que promueven la mantención y reproducción de un orden social discriminatorio e inhumano.

41 Al comparar con el año 2005 en donde lanzan la cuestionada campaña. Ver el análisis del conflicto en Venegas (2006b) y el análisis de las fotografías en Venegas (2007). 
La representación de Hombres y Mujeres en la publicidad estudiada no sólo se vale del entorno socio-cultural patriarcal y machista para generar un anclaje del sentido, sino además imprime una carga semiótica de inusitada violencia simbólica representando lo más abyecto del ser humano como es transformar en objeto a las personas, esto es, deshumanizándolas.

\section{Conclusiones y Discusión.}

En el análisis el discurso de la Campaña Publicitaria Otoño-Invierno de la tienda FES muestra el modo técnico y retórico tras del cual se oculta subyacente una renovada estrategia en la Sociedad del Control que tiene por finalidad no el reprimir la subjetividad social sino enmarcarla, haciendo de la publicidad el renovado mecanismo multiforme para presentarnos bajo la apariencia siempre nueva las mercancías hechas para calzar como pieza de un puzzle en la subjetividad de un hombre y mujer transformados en seres unidimensionales por la publicidad y la sociedad del consumo.

Si la publicidad estudiada ha ido en contra de los Derechos Humanos, la Constitución Política de la República de Chile, el Código de Ética Publicitaria y la Convención para la Eliminación de Todas las Formas de Discriminación contra la Mujer, se debe no sólo a la carencia de las regulaciones legales que faciliten la pronta retirada de este tipo de publicidad y las debidas sanciones, sino además, a tribunales de justicia capaces de operar con celeridad. A todo lo ya señalado se suma un aspecto no menor, la precaria formación cívica traducida en un desconocimiento de los derechos y/o el individualismo propio de los tiempos actuales.

La tienda FES ha violado sistemáticamente los derechos que protegen y salvaguardan el debido respeto de la persona humana, en consecuencia, una publicidad como esta no sólo debe ser enérgicamente repudiada, sino además, fortalecer la formación cívica a lo largo de toda la educación formal, haciendo una educación en y desde los Derechos Humanos. Estos deben asumirse por los movimientos ciudadanos capaces de visibilizar y denunciar estos hechos como otros que dañan la convivencia democrática.

Mientras más avanza el ocaso del Hombre y la Mujer deshumanizados como mercancías, más profundo debe volverse el compromiso de quienes practican la Psicología y en general, las disciplinas pertenecientes a las Ciencias Sociales. El presente ejemplo de análisis, significa avanzar en la dirección que promueve el cambio social respecto de aquellas condiciones de injusticia, por el único medio legítimo como es el discurso y acción comprometida con la verdad, la justicia y el pleno respeto a los derechos de las personas. Sin embargo, la enseñanza universitaria, las prácticas profesionales y el ejercicio profesional de la Psicología y de las Ciencias Sociales, ¿se encuentran en esta senda? 


\section{Referencias}

Baczko, B. (1999). Los imaginarios sociales. Memorias y esperanzas colectivas. Buenos Aires: Nueva Visión. (Orig. 1984).

Barthes, R. (1992). La imagen. En Lo obvio y lo obtuso. Imágenes, gestos, voces (pp. 11-27). Barcelona: Paidós. (Orig. 1961).

Boscán, J. \& Mendoza, M. (2004). Análisis semiótico de la publicidad de perfumes. Opción, 20, 75-93.

Bourdieu, P. \& Passeron, J-C. (2001). Fundamentos de una Teoría de la Violencia Simbólica. En La Reproducción. Elementos para una Teoría del Sistema de Enseñanza (pp. 13-85). Madrid: Popular. (Orig. 1970).

Bravo, N. (1995). Valores humanos. Por la senda de una ética cotidiana. Buenos Aires: RIL.

Calello, H. \& Neuhaus, S. (1999). Estructuralismo. En Método y antimétodo. Proceso y diseño de la investigación interdisciplinaria en Ciencias Humanas (pp. 79-87). Buenos Aires: Colihue.

Colegio de Psicólogos de Chile. (1999). Código de Ética Profesional. Extraído el 16 de Agosto del 2006, desde, http://www.colegiopsicologos.cl/documentos/codigoetica.PDF

Convención para la Eliminación de todas las Formas de Discriminación Contra la Mujer. (1979). Extraída el 10 de Julio del 2008, desde, http://www.unhchr.ch/spanish/html/menu3/b/e1cedaw sp.htm

Correa, G., Orellana, V., Varas, P., Zamora, S. (1992). Los valores. En Vivir mi adolescencia (pp. 14-33). Santiago: Salvador.

Clemente, M. (1997). Los problemas sociales: Qué son y cómo se manifiestan. En Psicología Social Aplicada (pp. 11- 28). Madrid: Pirámide. (Orig. 1992).

Consejo Nacional de Autorregulación y Ética Publicitaria. (2008, Mayo 16). Dictamen Ético. [No Publicado].

Deleuze, G. (1999). Post-Escriptum sobre las sociedades del control. En Conversaciones (19721990) (pp. 5-9). Valencia: Pre-textos. (Orig. 1990). Extraído el 16 de Agosto del 2008, desde, http://www.oei.org.ar/edumedia/pdfs/T10_Docu1_Conversaciones_Deleuze.pdf

Eisler, R. (1993). Un avance en la evolución: Hacia un futuro solidario. En El cáliz y la espada. Nuestro pasado, nuestro futuro (pp. 210-231). Santiago: Cuatro Vientos. (Orig. 1987).

FES (2008a). FES dice no a la violencia contra la Mujer. Extraído el 10 de abril del 2008, desde, www.fesjeans.com

FES (2008b). Amores que matan, show de cobardes. [Fotografías de la campaña publicitaria]. Extraído el 12 de abril del 2008, desde, www.fesjeans.com

FOTONOSTRA. (2008). Técnicas de composición. Extraído el 16 de Agosto del 2008, desde, http:// www.fotonostra.com/grafico/tecnicascompos.htm

Foucault, M. (1992). Verdad y poder. En La microfísica del poder (pp. 185-200). Madrid: La Piqueta. (Orig. 1977).

Franco, J. (2004). Escalas de Iconicidad. Extraído el 16 de Agosto del 2008, desde, http://www.ehu. es/francoiradi/DOCENCIA/APUNTES/ARCHIVOS_PDF/Escalas_de_iconicidad.pdf

Freund, G. (1995). Las relaciones entre las formas artísticas y la sociedad. En La fotografía como documento social (pp. 7-9). Barcelona: Gustavo Gili. (Orig. 1976).

Frondizi, R. (1990). ¿Qué son los valores? Introducción a la axiología. México: Fondo de Cultura Económica. (Orig. 1958). 
Geertz, C. (2001). Descripción densa: Hacia una teoría interpretativa de la cultura. En La interpretación de las culturas (pp. 9-40). Barcelona: Gedisa. (Orig. 1973).

Granger, G. (1970) Objeto, estructuras y significaciones. En Granger, G., Lévi-Strauss, C, Mantovani, G. Mouloud, N. \& Serres, M. Estructuralismo y epistemología (pp. 78-121). Buenos Aires: Nueva Visión, (Orig. 1965).

Hernández, A. (1973). Introducción al estudio del Estructuralismo y el Derecho. En Hernández, A., Núñez, L., Sobrado, J., Mesa, A., Peces, J. Pérez, J. Estructuralismo y Derecho (pp. 11-52). Madrid: Alianza. (Orig. 1973).

Hernández, R. Fernández, C. \& Baptista, P. (1998). Definición del tipo de investigación a realizar: básicamente exploratoria, descriptiva, correlacional o explicativa. En Metodología de la investigación (pp. 57-71). México: Mc Graw Hill, (Orig. 1991).

Iñiguez, L. (2003). Glosario. En Análisis del Discurso. Manual para las Ciencias Sociales (pp. 202207). Barcelona: UOC.

Las Últimas Noticias. (2006, Noviembre 20). Fundación Instituto de la Mujer presentó recurso contra publicidad de marca de ropa. Extraído el 2 de Agosto del 2008, desde, http://www.lnd.cl/ prontus noticias/site/artic/20061120/pags/20061120121718.html

Lechuga, L. (2005, mayo 19). Recurso judicial contra sangriento aviso. Las Últimas Noticias, p. 7.

Lévi-Strauss, C. (2001a). Sentido y uso de la noción de modelo. En Antropología estructural. Mito, sociedad, humanidades (pp. 71-81). México: Siglo XXI, 2001. (Orig. 1960).

Lévi-Strauss, C. (2001b). La estructura y la forma. En Antropología estructural. Mito, sociedad, humanidades (pp. 113-141). México: Siglo XXI. (Orig. 1960).

Lévi-Strauss, C. (2001c). Estructuralismo y crítica literaria. En Antropología estructural. Mito, sociedad, humanidades (pp. 259-262). México: Siglo XXI. (Orig. 1965).

López, R. (1992). ¿Qué son los valores? En Apuntes de Psicología (73-76). Santiago: Universidad Educares.

Martinic, S. (2006). El estudio de las representaciones y el análisis estructural de discurso. En Canales, M. (Coord.-Ed.). Metodologías de investigación social. Introducción a los oficios (pp. 299-319). Santiago: LOM.

Maturana, H. (1997) Conversaciones matrísticas y patriarcales. En Maturana, H. \& Verden-Zöller, G. Amor y juego. Fundamentos olvidados de lo humano desde el Patriarcado a la Democracia (pp. 19- 69). Santiago: Instituto de Terapia Cognitiva, (Orig. 1993).

Peirce, Ch. (1903). La ética de la terminología. En Peirce, Ch. (1986). La ciencia de la Semiótica (pp. 15-20). Buenos Aires: Nueva Visión, 1986.

PNUD. (2000). Las aspiraciones colectivas. En Más sociedad para gobernar el futuro (pp. 57-105). Extraído el 13 de abril del 2008, desde, http://www.desarrollohumano.cl/archivos/parte2.pdf

Posadas, F. (2008). La angulación. En La sintaxis visual. Extraído el 20 de Julio del 2008, desde, http://www.slideshare.net/actimoliner/la-sintaxis-visual

Rojas, E. (1989). El laberinto de la afectividad. España: Espasa-Calpe.

Sercovich, A. (1973). Presentación. Interpretantes para Charles Sanders Peirce: Semiótica e Ideología. En Peirce, Ch. (1986). La ciencia de la Semiótica (pp. 9-14). Buenos Aires: Nueva Visión (Orig. 1986).

Stake, R. (1999). El caso único. En Investigación con estudio de casos (pp. 15-24). Madrid: Morata. (Orig. 1995). 
Universidad Católica de Chile. (2008). Manual de patología general. Etiología general. Extraído el 28 de Septiembre del 2008, desde, http://escuela.med.puc.cl/publ/patologiageneral/Patol_011. $\underline{\mathrm{htmL}}$

Venegas, C. (2006a). La Modernización de la Justicia en Chile en el Discurso de Inauguración del Año Judicial 1994 y en un Discurso Oficial del Ministerio de Justicia, 1994. Revista de Ciencias Sociales, 51, 131-208.

Venegas, C. (2006b). Conflicto psicosocial jurídico entre Fundación Instituto de la Mujer y tienda FES por contenido de anuncio publicitario. Summa Psicológica, 3, (1), 3-22.

Venegas, C. (2007). Análisis Psicosocial Jurídico con Perspectiva de Género: Campaña publicitaria de la tienda FES. Summa Psicológica, 4, (2), 35-55.

Verón, E. (1987). La semiosis social. Fragmentos de una teoría de la discursividad. Barcelona: Gedisa, 1987. 
ANEXO: Fotografías Publicitarias de FES Campaña Otoño-Invierno 2008.

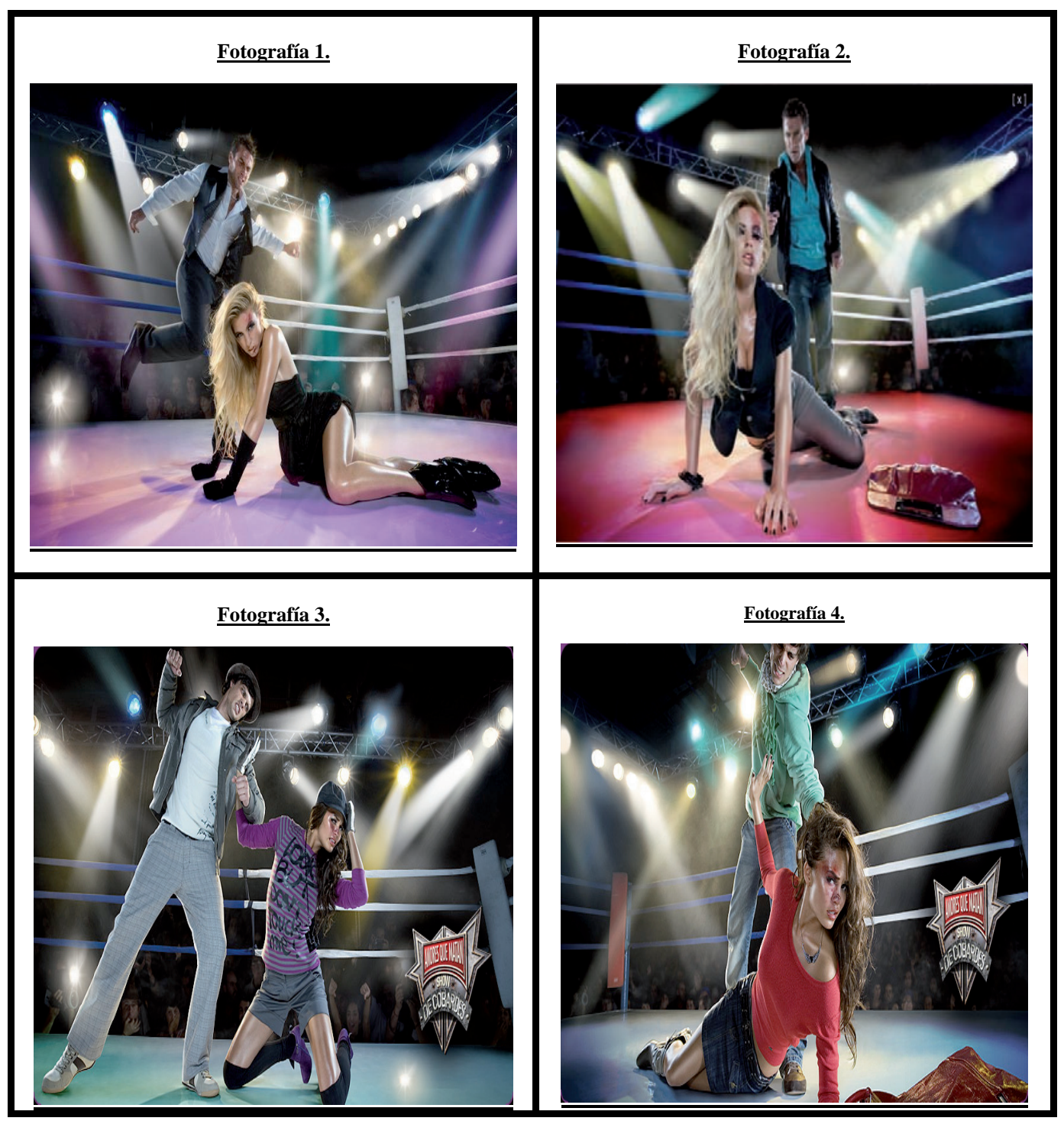

